\title{
Topical issue: advanced imaging and endovascular treatment in pulmonary artery diseases
}

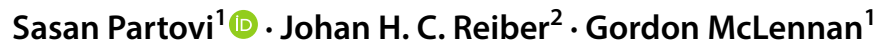

Received: 23 June 2019 / Accepted: 27 June 2019 / Published online: 10 July 2019

C) Springer Nature B.V. 2019

This topical issue of The International Journal of Cardiovascular Imaging is focused on advanced imaging and endovascular treatment of pulmonary artery diseases including a variety of imaging modalities and interventional techniques.

Pulmonary artery diseases encompass a wide spectrum of pathology from acute embolic disease to chronic conditions, such as pulmonary hypertension. The first line treatment for pulmonary embolism is anticoagulation. However sub-massive or massive pulmonary embolism are associated with a poor outcome and therefore there is growing evidence for catheter directed thrombolysis using a variety of techniques, such as ultrasound assisted approaches. In selected patient with chronic pulmonary embolism endovascular therapy can be indicated to potentially avoid pulmonary hypertension as a long-term sequela. Both, primary and secondary forms of pulmonary hypertension are associated with a decreased quality of life and high mortality. Innovative treatment approaches are warranted in the near future to treat pulmonary hypertension. Advanced imaging work-up, such as gadolinium enhanced MRI or post-processing methods, such as computational fluid dynamics may enable risk stratification as well as non-invasive disease severity assessment, thereby facilitating selection of patients for more aggressive treatment approaches, specifically endovascular therapy in addition to drug-based regimens.

The first part of this topical issue is including review papers from leading institutions and authors worldwide describing the current literature as well as future perspectives based on the authors' experience and expertise. The first paper by Rengier et al. discusses evolving imaging

Sasan Partovi

partovs@ccf.org

1 Interventional Radiology Section, Imaging Institute, Cleveland Clinic Foundation, 9500 Euclid Ave, Cleveland, OH 44195, USA

2 Department of Radiology, Leiden University Medical Center, Leiden, The Netherlands techniques for diagnosis and follow-up of pulmonary hypertension [1]. The second manuscript by Rajiah et al. focuses on multi-energy CT for the assessment of pulmonary vasculature [2] whereas the third manuscript by Aziz et al. elaborates around MRI for the evaluation of the pulmonary vasculature [3]. The next paper from Zucker describes the value of cross-sectional imaging in the setting of congenital pulmonary artery anomalies [4]. The manuscript from Kalra-Lall and colleagues discussed pulmonary artery aneurysms and pseudoaneurysms [5]. The paper from Javed and Sista deals with endovascular therapeutic options for massive and submassive pulmonary embolism [6]. Embolization techniques and outcomes for the treatment of pulmonary arteriovenous malformations are discussed based on extensive institutional experience in the review paper from Tellapuri et al. [7]. Imaging characteristics of pulmonary artery sarcoma and their surgical treatment is described in the paper form Wyler von Ballmoos and colleagues [8].

The second part of this topical issue is encompassing high quality original research papers dealing with different pulmonary artery disease entities including pulmonary artery reconstruction, pulmonary hypertension and endovascular pulmonary valve implantation. The paper from Zucker et al. investigates the use of $\mathrm{CT}$ angiography for preoperative planning of pulmonary artery reconstruction in pediatric patients and demonstrates the value of iodine maps in this context [9]. Doppler estimates of pulmonary vascular resistance were used to differentiate two different types of pulmonary hypertension in the heart failure population in the article by Venkateshvaran [10]. Dasatinib induced pulmonary arterial hypertension was investigated in a study by Toya et al. using clinical and imaging parameters [11]. The study of Liu et al. assessed the role of two-dimensional speckle tracking echocardiography in pre-capillary pulmonary hypertension [12]. The role of MR imaging for Tetralogy patients undergoing transcatheter pulmonary valve implantation was the focus of the research manuscripts from Leonardi et al. [13] and from Ebel et al. [14]. 
The papers of this topical issue of The International Journal of Cardiovascular Imaging are not intended to represent the entire field of pulmonary artery diseases. Though they represent a fine selection of strong review and original research articles, offering readers of the journal an opportunity to get a robust overview of imaging and interventions for a variety of pulmonary diseases. A fundamental understanding of this will be needed in the coming decades as research is conducted to develop and validate new therapies for this important disease spectrum.

\section{Compliance with ethical standards}

Conflict of interests The authors declare that they have no conflict of interest related to this editorial introduction.

Ethical approval No research involving human participants or animals was conducted.

\section{References}

1. Rengier F, Melzig C, Derlin T, Marra AM, Vogel-Claussen J (2018) Advanced imaging in pulmonary hypertension: emerging techniques and applications. Int J Cardiovasc Imaging https://doi. org/10.1007/s10554-018-1448-4

2. Rajiah P, Tanabe Y, Partovi S, Moore A (2019) State of the art: utility of multi-energy CT in the evaluation of pulmonary vasculature. Int J Cardiovasc Imaging https://doi.org/10.1007/s1055 4-019-01615-8

3. Aziz M, Krishnam M, Madhuranthakam AJ, Rajiah P (2019) Update on MR imaging of the pulmonary vasculature. Int J Cardiovasc Imaging https://doi.org/10.1007/s10554-019-01603-y

4. Zucker E (2019) Cross-sectional imaging of congenital pulmonary artery anomalies. Int J Cardiovasc Imaging https://doi. org/10.1007/s10554-019-01643-4

5. Kalra-Lall A, Donaldson J, Martin C (2019) Brief review: pulmonary artery aneurysms and pseudoaneurysms. Int J Cardiovasc Imaging https://doi.org/10.1007/s10554-019-01547-3

6. Javed QA, Sista AK (2019) Endovascular therapy for acute severe pulmonary embolism. Int J Cardiovasc Imaging https:// doi.org/10.1007/s10554-019-01567-z
7. Tellapuri S, Park HS, Kalva SP (2018) Pulmonary arteriovenous malformations. Int J Cardiovasc Imaging https://doi.org/10.1007/ s10554-018-1479-x

8. Wyler von Ballmoos MC, Chan EY, Reardon MJ (2018) Imaging and surgical treatment of primary pulmonary artery sarcoma. Int J Cardiovasc Imaging https://doi.org/10.1007/s10554-018-1489-8

9. Zucker EJ, Kino A, Schmiedeskamp H, Hinostroza V, Fleischmann D, Chan FP (2019) Feasibility and utility of dual-energy chest CTA for preoperative planning in pediatric pulmonary artery reconstruction. Int J Cardiovasc Imaging https://doi.org/10.1007/ s10554-019-01602-z

10. Venkateshvaran A, Hamade J, Kjellström B, Lund LH, Manouras A (2019) Doppler estimates of pulmonary vascular resistance to phenotype pulmonary hypertension in heart failure. Int J Cardiovasc Imaging https://doi.org/10.1007/s10554-019-01591-z

11. Toya T, Nagatomo Y, Kagami K, Yukino M, Yasuda R, Namba T, Ido Y, Kobayashi S, Masaki N, Yada H, Kimura F, Adachi $\mathrm{T}$ (2019) Computed tomography-measured pulmonary artery to aorta ratio and EUTOS score for detecting dasatinib-induced pulmonary arterial hypertension. Int J Cardiovasc Imaging https:// doi.org/10.1007/s10554-019-01548-2

12. Liu BY, Wu WC, Zeng QX, Liu ZH, Niu LL, Tian Y, Cheng XL, Luo Q, Zhao ZH, Huang L, Wang H, He JG, Xiong CM (2019) Two-dimensional speckle tracking echocardiography assessed right ventricular function and exercise capacity in pre-capillary pulmonary hypertension. Int J Cardiovasc Imaging https://doi. org/10.1007/s10554-019-01605-w

13. Leonardi B, Secinaro A, Perrone MA, Curione D, Napolitano C, Gagliardi MG (2019) Role of cardiovascular magnetic resonance end-systolic 3D-SSFP sequence in repaired tetralogy of fallot patients eligible for transcatheter pulmonary valve implantation. Int J Cardiovasc Imaging https://doi.org/10.1007/s10554-01901630-9

14. Ebel S, Gottschling S, Buzan MTA, Grothoff M, Dähnert I, Wagner R, Gräfe D, Lurz P, Gutberlet M, Lücke C (2019) 3D-assessment of RVOT dimensions prior percutaneous pulmonary valve implantation: comparison of contrast-enhanced magnetic resonance angiography versus $3 \mathrm{D}$ steady-state free precession sequence. Int J Cardiovasc Imaging https://doi.org/10.1007/s1055 4-019-01578-w

Publisher's Note Springer Nature remains neutral with regard to jurisdictional claims in published maps and institutional affiliations. 